\title{
Carlos Vives redefinindo o "local" Colômbia através de um vallenato world music
}

Carlos Vives redefining the "local" Colombia through a world music vallenato Laís Galo Vanzella e Francirosy Campos Barbosa

\section{(2) OpenEdition \\ 12 Journals}

Edição electrónica

URL: http://journals.openedition.org/aa/4031

DOI: $10.4000 /$ aa. 4031

ISSN: 2357-738X

Editora

Programa de Pós-Graduação em Antropologia Social (UnB)

\section{Edição impressa}

Data de publição: 1 dezembro 2019

Paginação: 305-328

ISSN: 0102-4302

\section{Refêrencia eletrónica}

Laís Galo Vanzella e Francirosy Campos Barbosa, «Carlos Vives redefinindo o "local" Colômbia através de um vallenato world music», Anuário Antropológico [Online], v.44 n.2 | 2019, posto online no dia 02 dezembro 2019, consultado o 27 abril 2021. URL: http://journals.openedition.org/aa/4031 ; DOI: https://doi.org/10.4000/aa.4031

\section{(c) (i) $\ominus$}

Anuário Antropológico is licensed under a Creative Commons Atribuição-Uso Não-Comercial-Proibição de realização de Obras Derivadas 4.0 International. 


\title{
Carlos Vives redefinindo o "local" Colômbia através de um vallenato world music
}

\author{
Carlos Vives redefining the "local" \\ Colombia through a world music vallenato
}

Laís Galo Vanzella

Faculdade de Filosofia, Ciências e Letras de Ribeirão Preto da Universidade de São Paulo - Brasil

Francirosy Campos Barbosa Faculdade de Filosofia, Ciências e Letras de Ribeirão Preto da Universidade de São Paulo - Brasil

\section{Introdução}

Qual a função da memória? Não reconstrói o
tempo, não o anula tampouco. Ao fazer cair a
barreira que separa o presente do passado, lança
uma ponte entre o mundo dos vivos e o do além,
ao qual retorna tudo o que deixou à luz do sol

(Bosi, 1994, p. 89).

Propomos apresentar, neste artigo, o que é a categoria world music e como essa se perfilou na Colômbia através do gênero musical vallenato e dos novos estilos de fusões musicais colombianas que surgiram nos anos 2000. Durante a pós-graduação e mestrado da primeira autora, a mesma acompanhou apresentações musicais, entrevistou ${ }^{1}$ musicistas, empresários do ramo musical, pesquisadores, radialistas e artistas, dentre eles, o cantor Carlos Vives, um dos maiores expoentes do vallenato world music na contemporaneidade.

Vives nasceu em 7 de agosto de 1961 em Santa Marta, Magdalena (Colômbia), onde viveu até os 12 anos de idade. Depois se mudou com sua família para Bogotá. Estudou publicidade e começou a tocar em bares e cafés ao redor da cidade. Na década de 1980 atuou em telenovelas e lançou seu primeiro 
álbum. Sua atuação como cantor e ator foi aos poucos ganhando projeção na cena colombiana.

Em 2009, durante uma visita ao Gaira cumbia house, bar do cantor Carlos Vives, descobri ${ }^{2}$ a existência de um gênero musical de nome curioso, que parecia ser conhecido por turistas do mundo todo, exceto do Brasil: o vallenato. Além disso, percebi que existiam debates rigorosos e festivais folclóricos que defendiam a preservação de seu estilo antigo em oposição às versões que as rádios e músicos modernos haviam internacionalizado. O que me pareceu mais relevante foi o lugar ocupado por Carlos Vives na mídia e no discurso de muitos colombianos: apesar de ter enfrentado diversas críticas quando apareceu com seu vallenato híbrido, ele aparentava ser muito benquisto, inclusive pelos defensores do folclore nacional. A história de Carlos Vives e de seu vallenato me fez voltar ao país para estudá-la em 2011 e, novamente, em 2016.

A pesquisa de campo foi realizada em dois períodos: março de 2011 e fevereiro de 2016. No ano de 2011, colhi material para minha monografia de pós-graduação em Jornalismo Cultural. Nesse primeiro trabalho, estava estudando não somente o vallenato, mas também a cumbia. A monografia e o documentário produzidos em 2011 tinham como objetivo descobrir como trabalham as forças a favor da modernização desses dois gêneros musicais e se ainda existem movimentos contrários a essas mudanças, com discursos e normas conservadoras. A segunda ida ao campo ocorreu durante a pesquisa do mestrado, em 2016, ${ }^{3}$ e pretendeu compreender de que forma o vallenato possibilita o acesso a alguns elementos da memória coletiva/ individual colombiana.

As memórias musicais perpassam a minha vida. Eu poderia dizer, de forma sucinta, que a minha ligação com a Colômbia começou por meio da convivência que tive em 2009 com alguns colombianos em São Paulo, pois as suas narrativas me incentivaram a conhecer tal país naquele mesmo ano, mas esse primeiro contato não teria o mesmo significado se não fosse ao encontro da minha história, com as memórias que já habitavam em mim.

Tenho uma ligação muito forte com a música: desde as minhas primeiras lembranças me vejo acompanhada de um rádio. Recordar através dos cheiros e das músicas é, para mim, um prazer e a forma mais intensa de conexão com o fato lembrado. Mesmo tendo uma ligação mnemônica com a música, nunca nenhuma havia me deixado tão envolvida em sua performance como a colombiana, tanto dentro do contexto no qual eu me encontrava em São Paulo, quanto na minha primeira viagem ao país. E destaco exatamente esses dois 
momentos, pois neles me vi imersa nas melodias e nas narrativas das músicas.

Certas de que as questões e sensações não se esgotam, neste texto buscamos apresentar uma parte das pesquisas realizadas durante todos esses anos. Partimos da explicação do conceito de world music para estudar esta categoria na América Latina e, por fim, abordar o caso do vallenato colombiano.

\section{A categoria world music e a sensação de pertencimento a um "local"}

Jocelyne Guilbault (2006) interpreta o termo “world music” como um rótulo com referências ambíguas e significados multifacetados. Isso porque nenhum consenso seria alcançado em relação ao significado do termo: as variações dependem do país que realiza essa definição, da posição social de quem define, da gravadora etc. No caso da autora, ela se refere ao tipo de música popular que surgiu nos anos 1980, foi massificada e distribuída para o mundo todo e está associada a grupos e países pequenos em desenvolvimento.

A world music combina elementos de músicas locais com músicas mainstream ${ }^{5}$ no mercado transnacional industrial atual e alcançou os mercados dos países industrializados com gêneros musicais como o soukous, rai e zouk ${ }^{6}$ (Guilbault, 2006). Essa categoria é definida como:

Um termo de marketing descrevendo os produtos da fertilização musical cruzada entre o Norte - Estados Unidos e Europa Ocidental - e o Sul - principalmente África e o Caribe, que começou a aparecer na paisagem da música popular no início dos anos 1980 através do surgimento de infraestruturas comerciais novas e interligadas estabelecidas especificamente para cultivar e nutrir o apetite dos ouvintes do primeiro mundo por novos sons exóticos (Pacini-Hernandez, 1993, p. 48-50, tradução própria).

A chegada formal da world music, em 1987, foi o resultado do entrelaçamento entre comércio e cultura na apropriação de fragmentos culturais considerados “autênticos", destinados às audiências ocidentais cosmopolitas ávidas por um produto novo, exótico e diferenciado (Connell; Gibson, 2004).

Por um lado, essa categoria musical tira vantagem das habilidades e recursos das tradições dominantes: apropria-se de última tecnologia e conhecimento de produção, marketing e distribuição e apresenta muitas das características inerentes às músicas mainstream escutadas no mercado global. "Ao fazer isso, utiliza como se fosse uma língua franca, se não entendida, pelo menos reconhecida por todos” (Guilbault, 2006, 
p. 139, tradução própria). Entretanto, músicas como o zouk, rai e soukous mesclam atributos musicais de uma cultura particular considerada "autêntica”.

O resultado dessas estratégias de composição (língua franca com culturas particulares) significou um maior acesso ao mercado musical controlado pelas tradições dominantes (Guilbault, 2006). Contudo, o que determina, de fato, quais artistas ou músicos recebem a etiqueta de world music? Connel e Gibson (2004) afirmam que toda música é world music, no sentido de que é uma apresentação perene de todas as sociedades pelo mundo, mas somente algumas são rotuladas como tal.

Fela Kuti, por exemplo, músico nascido na Nigéria e criador do gênero afrobeat, que sincroniza jazz, funk, highlife e ritmos tradicionais africanos seria considerado world music? (A origem do afrobeat, 2016).

Nos anos 1960 e 1970, Kuti se destacou por protestar contra os regimes políticos autoritários em seu país e em toda a África (A origem do afrobeat, 2016). Muitas de suas músicas eram gravadas para criticar tais regimes, e ele foi detido mais de cem vezes, preso e espancado. Além das ditaduras africanas, o cantor também se mostrou contrário às corporações multinacionais, como fica nítido na letra de International Thief Thief (Culshaw, 2014).

O músico, enquanto estava vivo, ficou muito famoso na África e na Inglaterra, mas sua música quase não foi vendida no Ocidente. Ele gravava algumas de suas canções em inglês para que certos países africanos compreendessem, não para ser reconhecido pelo público ocidental. Kuti rejeitava as empresas ocidentais, pois as via como imperialistas (Culshaw, 2014).

Fela Kuti não quis a melodia beatle de Paul McCartney no seu afrobeat. Nem o selo Motown na sua seminal discografia. Quando sugestionado sobre a diminuição do tempo de suas músicas para torná-las mais acessíveis ao mercado fonográfico americano, Fela respondeu com afrobeats de 15 longos, luminosos e subversivos minutos. Por ter sido radicalmente avesso a padronizações, a qualquer proposta que pudesse levar sua arte a um estado de domesticação ou desfiguracão, Fela Kuti se tornou um ícone da música como instrumento de libertação, munição ou arma do futuro (Freitas, 2011).

A etiqueta "world music" transforma a música "local" para agradar mercados e gostos ocidentais, segundo John Connell e Chris Gibson (2004). No caso de Fela Kuti, suas músicas não foram registradas por gravadoras norte-americanas e nem compostas para agradar a um público amplo que buscava o exotismo de lugares par- 
ticulares. Elas eram críticas e contestadoras, feitas para serem ouvidas por africanos, portanto, não se encaixariam no rótulo de “world music". A resistência do artista, porém, não impediu que suas canções fossem posteriormente apropriadas pelo mercado e se tornassem world music nos anos 2000: "A música de Fela - ou o gênero fundado por ele, o afrobeat - toca em festinhas hypadas por aí pelo som de gente como Vampire Weekend ou Damon Albarn, todos reconhecendo sua genialidade por aí, pegando emprestado elementos do seu som" (Culshaw, 2014). Ainda: "A inserção de Fela no mainstream ocidental foi impulsionada pelo musical Fela!, produzido em parceria com Jay Z e apresentado em Londres e na Broadway em 2010. Foi lançado também um filme, Finding Fela, dirigido por Alex Gibney, que está sendo exibido em cinemas dos EUA e Europa" (Culshaw, 2014).

Mas o que faz a world music ser tão bem-aceita por ouvintes de todo o mundo? Connell e Gibson (2004) argumentam que os processos de migração, comercialização e as matrizes globais de mídias causam uma sensação de desterritorialização na pós-modernidade. Dessa forma, permanece a sensação de que perdemos nossas identidades culturais, antes relacionadas à nação.

As gravadoras e músicos começam a buscar novos ritmos que deem a ilusão de autenticidade e de pertencimento aos ouvintes. Portanto, a música vai ter um papel fundamental no preenchimento dessa nossa sensação de desterritorialização, pois será utilizada para redefinir o "local” (Connell; Gibson, 2004).

De acordo com Renato Ortiz (1996),

quando nos referimos ao "local", imaginamos um espaço restrito, bem delimitado, no interior do qual se desenrola a vida de um grupo ou de um conjunto de pessoas [...]. O "local" se confunde assim com o que nos circunda, está "realmente presente" em nossas vidas. Ele nos reconforta com sua proximidade, nos acolhe com sua familiaridade. Talvez por isso, do contraste em relação ao distante, do que se encontra à parte, o associemos quase que naturalmente a ideia do "autêntico" [...]. O desenraizamento é visto, portanto, como uma perda, um perigo, uma ameaça (Ortiz, 1996, p. 58).

Se o "local", segundo Ortiz, é o ambiente no qual nos sentimos protegidos do mundo porque nos é familiar e seguro, a cultura "local" seria, portanto, aquela que surge dentro das comunidades de uma nação. Ali, o indivíduo forma seus valores regionais, ali ele se reconhece. Nada mais correto do que dizer que o folclore, que surge no seio das comunidades locais, também nos dá essa sensação de segurança. 
Para Fiona Ritchie, apresentadora do programa americano Thistle and Shamrock, quando você ouve alguma coisa que parece que vem do coração de alguém, ela fala de coração para coração. . . as pessoas querem se conectar a algo que pareça que é de algum lugar. Tantos de nós nos sentimos sem teto. Nossas famílias se mudam tanto. Músicas assim dão às pessoas a oportunidade de se conectarem a algo que as transporta para casa (Johnson, 2003 apud Connell; Gibson, 2004, p. 353-354, tradução própria).

$\mathrm{Na}$ world music, a música popular, a etnicidade e a localidade se tornaram "fetiches disfarçando as forças globais dispersas que, na verdade, dirigem o processo de produção” (Appadurai, 1990, p. 16, tradução própria). Mais do que isso, os lugares foram promovidos como os berços da autenticidade (Connell; Gibson, 2004).

A recente e evidente preocupação, segundo Guilbault (2006), das culturas dominantes tradicionais em definir o "local" pode, portanto, ser interpretada como manifestação da sensação de desterritorialização. Já a questão dos países pequenos e em desenvolvimento de quererem definir o "local" parte de duas perspectivas: para alguns, é uma reação ligada ao medo de perder a identidade cultural diante da homogeneização mundial; para outros, uma oportunidade de redefinir e promover a identidade cultural "local" (Guilbault, 2006).

Sobre a identidade cultural, Sylvia Caiuby Novaes (1993) defende que essa é uma condição forjada a partir de determinados elementos históricos e culturais. Tal identidade é invocada sempre que um grupo reivindica uma maior visibilidade social devido ao apagamento a que foi historicamente submetido.

A autora dá o exemplo do Primeiro Encontro das Nações Indígenas no Brasil em 1982, que reuniu cerca de trezentos líderes indígenas, representantes de várias nações. Eles tinham o propósito de demonstrar que existiam em lugares nos quais os julgavam como extintos. Para tal, alguns grupos: "[...] compareceram ao evento com cocares, tacapes e outros adereços “típicos de índios”, muitos dos quais não são mais utilizados cotidianamente, numa clara tentativa de demonstrar, publicamente, a sua identidade diferenciada" (Caiuby Novaes, 1993, p. 65).

Para enfrentarem o mundo precisaram utilizar a "categoria índio" criada pelos ocidentais. Foi através dessa identidade forjada, o "nós índios", que conseguiram se organizar e apresentar suas reinvindicações ao governo e à sociedade de um modo geral (Caiuby Novaes, 1993).

A questão da busca por uma identidade cultural, seja ela nacional (época da modernidade) ou no mundo pós-moderno e globalizado, é bem definida por Stuart 
Hall (2011). De acordo com esse autor, a característica que mais definiu a modernidade foi o fato de os Estados tentarem se organizar sob a forma de culturas nacionais, ou seja, homogeneizar os diferentes tipos de cultura "local” encontrados dentro da Nação na forma de uma única cultura. Então, ou elas são modificadas para aderirem à forma homogênea ou são marginalizadas. ${ }^{7}$ Do mesmo modo, Anthony Giddens (1990, p. 37-38) considera que a constituição das práticas sociais é constantemente examinada e reformada à luz das informações recebidas.

Ortiz (1996) afirma que, com o ideal nacionalista moderno, os países tentam sufocar os costumes menores, ou aqueles que não são interessantes para o turismo, o mercado, a elite etc. Interessam apenas alguns fragmentos de cultura "local", que são combinados de forma calculada para formarem o folclore como é conhecido hoje.

Para Néstor Canclini (2001), somente quando o mercado na pós-modernidade fica saturado de tanta massificação cultural, a retomada de uma época "ingênua" e autêntica, pertencente a um "local” específico, se torna interessante. Para tal, não é necessário conhecer aquela cultura, somente resgatá-la, usando o próprio termo do autor. ${ }^{8}$

José Jorge de Carvalho (1991) comenta que a simbólica da cultura "local", assim como da cultura clássica, é basicamente pré-moderna e se apresenta como atemporal. Possui a capacidade de repetir-se infinitas vezes, mudando apenas sua forma de apresentação. Segundo o autor, é esse movimento que lhe dá sua personalidade distinta.

Para Hall (2011), a apropriação do "local" pode ocorrer de duas formas: uma delas é o fortalecimento de identidades locais, da tradição em sua forma "pura" e original, no sentido de "[...] recobrir as unidades e certezas que são sentidas como tendo sido perdidas” (Hall, 2011, p. 87). No caso da volta à tradição, ela é uma "[...] forte reação defensiva daqueles membros dos grupos étnicos dominantes que se sentem ameaçados pela presença de outras culturas” (Hall, 2011, p. 85). A segunda forma é a tendência à tradução, ou seja, a aceitação de que as identidades são influenciadas pela globalização e não são puras, unitárias. Nela, encontram-se as hibridações, as mesclas culturais. A tradução é o resultado do cruzamento de tradições culturais com culturas já internacionalizadas (Hall, 2011), sendo composta por pessoas que "[...] [retêm] fortes vínculos com seus lugares de origem e suas tradições, mas sem a ilusão de um retorno ao passado" (Hall, 2011, p. 89). Assim sendo, é dentro do movimento da tradução que se encontraria a categoria denominada world music. 


\section{World music na América Latina}

Canclini (2001) destaca que, na América Latina do século XIX, as elites abominavam a cultura popular, queriam substituí-la por aquela moderna e industrializada, nos moldes encontrados nos Estados Unidos e países economicamente desenvolvidos da Europa. A valorização do "local" só iria acontecer após a massificação da cultura pelo mercado.

A solução encontrada pela elite de cada país, na urgência de uma nova forma de distinção social, é o "resgate" (ver nota 8) da cultura popular, já quase esquecida em seu "local", é buscar refugiar-se em uma antiguidade idealizada. A cultura popular foi elevada ao status de "pura" e espiritualizada, e a cultura de massa passa a ser abominada e destinada ao restante da população (Canclini, 2001).

Durante a elaboração deste artigo, surgiu a seguinte pergunta: de quais gêneros musicais da América Latina a indústria da world music mais se apropriou e se apropria até hoje? Contudo, na busca entre artigos, websites, blogs e obras literárias, não foram encontradas informações suficientes para responder a tal questionamento. $\mathrm{O}$ que veio à baila foram definições do que seria a world music de uma forma mais ampla. Um fato que parece interessante e traz vários desdobramentos é a homogeneização do conceito de world music para contextos tão diversos e plurais como os latino-americanos e africanos. Os países tradicionalmente colonizadores e donos do mercado procuram nos países do terceiro mundo os elementos de exclusividade, mas contraditoriamente acabam nivelados em uma mesma categoria de mercado.

É possível ter uma ideia de quais países tiveram seus gêneros musicais apropriados quando são estudados os websites das gravadoras, como a famosa Putumayo Records. ${ }^{9}$ Os CDs lançados pela empresa contêm gêneros dos Estados Unidos e Europa e world music de origem africana e latina, como no caso do Brasil, a exemplo de samba e bossa nova fusionados com jazz. Um outro CD denominado Brazilian Lounge traz a seguinte descrição: "Melodias sedutoras brasileiras e mix eletrônico sutil nessa coleção de ritmos relaxantes contemporâneos" (tradução própria). A definição "sedutora" traz a ideia da exotização apontada por Darío Blanco Arboleda: "A world music [...] gera uma inércia de busca e exotização dos sons da alteridade para ser consumido pelo Ocidente” (Blanco Arboleda, 2009, p. 113, tradução própria). Além de CDs que fusionam o jazz com samba e MPB e de música eletrônica com "melodias brasileiras sensuais", encontram-se sons de todos os países da América Latina. Cuba é aquele com mais CDs dedicados a seus ritmos, seguido por México, Brasil e Colômbia. O interessante é que, além de músicas latinas e afri- 
canas, podem ser escutadas também músicas das Filipinas e de New Orleans, nos Estados Unidos, por exemplo, algo que nos faz questionar: qual seria o critério para encaixar-se no mercado world music?

Tomas Cookman, presidente da gravadora norte-americana Nacional Records, afirma que ela existe desde 2004 e que a ideia partiu de uma visão de mercado, porque, naquela época, não havia nos Estados Unidos uma gravadora focada no estilo música latina alternativa e que buscasse sons em lugares mais remotos de cada país, fusionados com ritmos internacionais (Tomas Cookman, entrevista, julho de 2011). ${ }^{10}$ Cookman comenta que não trabalha com o pop latino porque lhe interessam muito mais os sons locais e alternativos das regiões de cada país (Tomas Cookman, entrevista, julho de 2011).

\section{O vallenato world music na Colômbia}

“A princípio, meu conceito de folclore é muito diferente do que eu vejo que existe na indústria de uma maneira convencional" (Carlos Vives, entrevista, março de 2011). ${ }^{11}$

Se existe, de acordo com Hall (2001), na pós-modernidade a tendência à tradução, como foi exposto mais acima neste artigo, o gênero musical vallenato seria o maior exemplo de música colombiana considerada "pura", tradicional e "local" que foi hibridada e difundida em nível internacional, principalmente a partir do início da década de 1990, com o cantor Carlos Vives (Wade, 2000; Bermúdez, 2005; Figueroa, 2007; Blanco Arboleda, 2009).

Sobre as características desse gênero, Bermúdez (2004; 2005) afirma que o acordeão de botões é seu instrumento principal, além de outros dois obrigatórios: a caja vallenata ${ }^{12}$ e a guacharaca ${ }^{13}$. Já a inserção de instrumentos modernos é uma opção adotada por alguns artistas e recusada por outros. O cantor é sua figura central, seguido pelo acordeonista e demais músicos.

Segundo José Fontalvo Portaccio (2010), o vallenato possui quatro estilos tradicionais (ou aires, como são chamados): a puya, o son, o merengue e o paseo vallenato.

Há duas visões sobre o surgimento do vallenato: uma delas diz que a música de acordeão era nativa da região da Provincia, no litoral caribenho colombiano, mais especificamente da cidade de Valledupar, e foi interpretada ao longo do século XIX por músicos locais de uma forma "pura”, poética e sem interesses lucrativos. Com o 
passar do tempo, essa música foi ficando gradualmente comercializada e adquirindo o nome genérico de vallenato, às vezes se degenerando nos estágios mais avançados. Essa narrativa é contestada por aqueles que mantêm que o vallenato é um estilo de música coerente e que emergiu somente em 1940, pela mediação direta de elites locais, procurando exatamente a particularidade que as narrativas tradicionalistas ajudam a manter (Wade, 2000).

Durante a pesquisa, pude concluir que o vallenato, como gênero musical, de fato surgiu apenas na década de 1940. É resultado de uma estratégia política que ajudou a construir uma imagem regional, posteriormente nacional, positiva da Colômbia (Figueroa, 2007).

Desde sua emancipação do colonialismo espanhol, a população colombiana que vivia longe do centro político, nos litorais, se sentia marginalizada, esquecida perante as decisões do governo, sendo tratada como inferior. A Colômbia enfrentou diversos conflitos internos, e os mais violentos tiveram início em 1948, com o período chamado La Violencia (Blanco Arboleda, 2005; Leon Rincon, 2016). O interior do país experimentou mais os efeitos desse período do que os litorais: cidades como Bogotá tornaram-se ambientes perigosos para seus moradores, os quais passaram, pouco a pouco, a enxergar os litorais como um lugar de paz, de escape (Vanzella, 2018).

Alfonso López Michelsen, político liberal do litoral caribenho, foi um dos grandes responsáveis por essa mudança de imagem. Ele, juntamente com alguns políticos e intelectuais, como Gabriel García Márquez, percebeu que essa poderia ser a oportunidade para modificar a ideia que o interior tinha da Costa do Caribe e divulgar o novo departamento que estava formando ali, denominado "Cesar". Uma das estratégias dessa elite litorânea foi a de unificar as músicas existentes da Costa do Caribe ${ }^{14}$ em torno de um único nome: vallenato, que teria nascido em um só "local", Valledupar, a capital do novo Cesar. Logo, o vallenato foi parte de um plano intelectual e político que pretendeu criar, a partir do final da década de 1940, uma identidade cultural para a região da Provincia e, principalmente, para Valledupar (Vanzella, 2018).

Mais tarde, o gênero se tornou parte do folclore da Colômbia, e as lendas e histórias presentes nas canções de épocas remotas são defendidas até os dias atuais, não só por intelectuais mas por grande parcela da população. Desta forma, o vallenato é parte da tradição e da identidade cultural do país. Principalmente devido aos conflitos internos pelos quais o país passou, à imagem negativa difundida pela mídia 
associada ao tráfico de drogas, ao perigo, ao paramilitarismo, às FARC e outros, na Colômbia, o folclore tornou-se uma forma de pertencer, de compartilhar algo positivo (Blanco Arboleda, 2005). ${ }^{15}$

O cantor Carlos Vives teria sido o primeiro a conseguir fama nacional e internacional ao hibridar esse gênero considerado tradicional, "intocável” e "puro", exibindo um comportamento típico da modernidade: a fusão da arte tida como "pura" com instrumentos do rock e mesclas do pop. Tal hibridação gerou discussões sérias com foco na preservação da tradição colombiana, a exemplo do Fórum Nacional sobre preservação do vallenato, em abril de 2007 (Blanco Arboleda, 2005). À medidaque Carlos Vives, em suas produções discográficas, se distanciou do formato tradicional do vallenato, hibridando suas dimensões estilísticas com elementos musicais de outras fontes sonoras, gerou um desencanto entre os cultivadores tradicionais do gênero. De fato, Barbero e Ochoa Gautier (2001) argumentam que, na música, o emotivo da memória se encontra com o emotivo do sonoro, e várias esferas perceptivas e emotivas do sujeito podem envolver-se. Por isso, ela gera campos extremamente defensivos e estáticos.

A música ultrapassa as fronteiras dos meios e reconstitui a relação entre desejo e corpo, "tornando-se, assim, um terreno tremendamente fértil para transferir os velhos relatos da autenticidade e da memória, que ali se carrega, aos novos espaços da cultura globalizada" (Barbero; Ochoa Gautier, 2001, p. 117, tradução própria). É devido a essa multiplicidade de canais, de mensagens e sinestesias produzidas que música tem sido sempre elemento fundamental nas construções identitárias (Blanco Arboleda, 2009).

Para Nathaly Gómez (2015), a música, por sua natureza simbólica e por ser uma das expressões culturais presentes em todas as comunidades, enriquece a vida cotidiana, possibilita o desenvolvimento perceptivo, cognitivo e emocional, fortalece valores individuais e coletivos e se constitui em um dos fundamentos do conhecimento social e histórico.

Paula Guerra (2016) afirma que se a música reflete na construção de identidade dos indivíduos, também os festivais (na qualidade de eventos de consumo coletivo de música) são cenários possíveis dessas funções. Eles teriam “[...] uma forte importância na construção identitária (especialmente se tivermos em linha de conta que muitos de seus espectadores atualmente são jovens) nos consumos, e nas formas "modernas" de apropriação cultural" (Guerra, 2016, p. 21).

Guerra (2016) argumenta que, em um mundo de crescente fragmentação cul- 
tural e identitária, a sensação de localidade aparece de diversas formas, e uma delas seria através dos festivais tradicionais:

O festival tem vindo a surgir como uma resposta aos processos de mobilidade e de globalização cultural. Esta resposta centrada nos festivais está focada na procura e no encontro de um significado acerca da identidade, da comunidade e da pertença. Na sua maioria, os festivais são uma síntese da dualidade representada pelo "local" e pelo global num contexto de mudança: são o compromisso entre permanência e vertigem (Guerra, 2016, p. 3-4).

Os dois festivais mais importantes do gênero vallenato na Colômbia são o Festival de La LeyendaVallenata e o Festival Cuña de Acordeones. O primeiro foi declarado patrimônio cultural imaterial da humanidade pela UNESCO, em 2015. Ocorre todo mês de abril em Valledupar, e cantores do país todo se reúnem na cidade para prestigiarem os diferentes aires (estilos) de vallenato permitidos no evento. A cada ano há premiações em diferentes categorias e dentre elas está a de melhor acordeonista (Vanzella, 2011; 2018). Já o Festival Cuña de Acordeones acontece todo mês de setembro no município de Villanueva, departamento de La Guajira. É declarado patrimônio cultural e artístico nacional desde 2006 (Vanzella, 2011). Enquanto o Festival Cuña de Acordeones permanece menor e quase imutável ao longo dos anos, La Leyenda Vallenata atrai cada ano mais músicos, turistas, profissionais de imprensa e fica menos rígido em suas normas. O evento é, também, de grande importância para a economia do "local" (Nicolas de Los Ríos, entrevista, fevereiro de 2016). ${ }^{16}$

Guerra (2016) explica que, sobretudo, os festivais que atingem uma maior dimensão são perspectivados como fatores de desenvolvimento econômico "local". Esses eventos seriam associados a ideias positivas, como no caso do festival de Portugal Sudoeste, que tem sua imagem conectada ao verão, sol, praia etc. Esses símbolos são verdadeiros cartões de visita para o "local".

O processo de valorização da Costa do Caribe e do vallenato como um gênero musical que a representasse teria começado no final da década de 1940, mas sua consolidação somente ocorreria nas décadas de 1960 e 1970, com a criação do departamento de Cesar e do Festival de La Leyenda Vallenata (Vanzella, 2018): “A consolidação do vallenato como uma tradição nascida na região denominada Província ocorreu em 1968 com o início do Festival de la Leyenda Vallenata" (Wade, 2000, p. 178, tradução própria).

Durante todo esse período até os dias atuais, músicos, intelectuais e o governo 
regional lançaram diversas campanhas que associavam o Caribe colombiano com a alegria. Essas imagens se tornaram cartões de visita para a região e, posteriormente, para a Colômbia como um todo, sendo utilizadas também pelo governo nacional na tentativa de sobrepor tais símbolos de felicidade àqueles negativos já citados neste $\operatorname{artigo}^{17}$ (Vanzella, 2018).

O patrimônio existe como força política na medida em que é teatralizado: em comemorações, monumentos e museus [...]. A comemoração tradicionalista é frequentemente baseada no desconhecimento do passado. Dado que esta versão do culto é sustentada por grupos oligárquicos, pode-se supor que sua "ignorância" se deve ao interesse por preservar os privilégios que conquistaram no período idealizado (Canclini, 2001, p. 159-164, tradução própria).

O vallenato se constitui, portanto, como uma ferramenta de criação e perpetuação de tais símbolos de felicidade, pois é através das histórias criadas sobre sua origem remota e das letras das canções que ajuda a manter a tradição "local". A hibridação cultural difundida pelos músicos vallenatos nas rádios e nos festivais do gênero mobilizou estruturas antigas, mexeu com questões identitárias e a imagem de alegria e de "pureza" entoada em tais canções. Temendo mudanças no folclore e tentando impedir que as novas modificações no gênero chegassem até os palcos dos dois festivais vallenatos mais importantes do país (citados mais acima neste artigo), o presidente da Fundación Festival de la Leyenda Vallenata, Rodolfo Molina Araújo, afirmou, no Fórum de 2007:

Queremos afiançar o vallenato puro em suas quatro expressões, paseo, merengue, son e puya, para transformá-lo em uma música rentável à industria e produtiva para o artista, sem que perca as características de sua origem, nem na sua estrutura melódica, nem na sua linha de composição poética de costume e de raiz (Rodolfo Molina Araújo, 2007 apud Portaccio, 2010, p. 136, tradução própria).

Nas hibridações contemporâneas das músicas regionais ocorre uma ruptura radical entre música e espaço. Esta, por sua vez, reformula radicalmente as políticas da memória (Barbero; Ochoa Gautier, 2001).

Se, na opinião dos tais “cultivadores do gênero" houve uma deformação progressiva no vallenato hibrido, então que grupos defendem e estimulam essas modernizações de gêneros considerados tradicionais? Nas palavras do cantor Carlos Vives, seriam principalmente: "O público jovem e a indústria da música internacional que 
estavam buscando novos sons na década de 1990, algo que pudesse mostrar para o mundo as tradições da Colômbia” (Carlos Vives, entrevista, março de 2011).

Em 1980 e 1990, alguns músicos e grupos começaram a modernizar o vallenato, mas quebraram todas as regras existentes, ou seja, não era possível nem mesmo reconhecer a qual gênero pertenciam (Vanzella, 2018). A proposta de Carlos Vives transformou o vallenato em duas vias contrapostas: por um lado, o artista o "modernizou", por meio da instrumentação eletrônica e mescla com gêneros, como o rock, pop, ska, reggae etc; por outro lado, o "tradicionalizou", reincorporando instrumentos indígenas, como a gaita hembra ${ }^{18}$, que havia desaparecido das performances no século XX (Blanco Arboleda, 2009). "O perfil indígena foi mais fácil de comercializar do que o afro na Colômbia, pois esta revalorização étnica encaixou de maneira evidente na indústria musical, de acordo com as diretrizes de categorias comerciais como a world music" (Blanco Arboleda, 2009, p. 113, tradução própria).

Carlos Vives teve a combinação de elementos perfeita para entrar no mercado das tradições dominantes, comenta Peter Wade (2000). O primeiro disco do cantor nesse gênero foi uma regravação de clássicos da região vallenata com características sonoras mais modernas. "Os arranjos soaram bem tradicionais e tinham a intenção de manter o espírito dos anos 1950, quando as músicas foram compostas" (Wade, 2000 , p. 216, tradução própria). Além disso, a instrumentalização proeminente era constituída de acordeão, caja vallenata e guacharaca, os três primeiros instrumentos considerados "autênticos" do gênero (Wade, 2000).

O projeto de reviver canções clássicas vallenatas foi do próprio cantor. Os melhores artistas e arranjos foram utilizados, e o disco Classicos de La província foi lançado em 1993. O álbum foi uma grande conquista, quebrou todos os recordes de vendas do país e foi vendido no México, Espanha e até nos Estados Unidos, onde Vives ganhou um disco de ouro e foi nominado ao Grammy. O cantor quebrou barreiras também de classe social, já que pessoas de classe média (incluindo intelectuais que geralmente depreciavam o vallenato) estavam entre os compradores.

A primeira canção composta e interpretada por Carlos Vives que ficou internacionalmente conhecida é de 1995, chamada La tierra del olvido. A letra é um hino à Colômbia, uma tentativa de modificar a imagem achatada produzida pela mídia, de que a nação seria somente caracterizada por fatos ruins em sua história. Esse lançamento, de enorme sucesso mundial, fez o artista, sua música e a Colômbia ficarem conhecidos globalmente através de uma outra imagem, a de um país cheio de belezas naturais e de gente alegre e receptiva. Carlos Vives conseguiu, com canções como La 
tierra del olvido, El amor de mi tierra e muitas outras (que reproduziam o clima camponês da Colômbia do século XVIII, com batidas vibrantes modernas), mostrar um novo ângulo do país na mídia de todo o mundo, além de redefinir o "local” Caribe e o "local" Colômbia como mágicos, alegres e poéticos, atingindo principalmente um público jovem que, antes dele, nunca havia comprado um CD de vallenato.

Parte do sucesso de Vives, relata Wade (2000), se deve ao seu visual de jeans e couro no palco, contrastando com o estilo do seu acordeonista Egidio Cuadrado, que tinha reputação impecável em meio aos tradicionalistas do gênero porque já havia ganhado o prêmio do Festival de la Leyenda Vallenata, em 1985. Carlos Vives demorou a ser aceito no meio artístico como um representante da música vallenata, e, em sua entrevista, confessou que, até hoje, muitos o acusam de degradar o verdadeiro folclore. O cantor defende sua posição dizendo que nunca pretendeu fazer folclore: a tradição é apenas uma inspiração para seu estilo pessoal, o qual é uma mescla de memórias da sua infância em Santa Marta (cidade do litoral caribenho) com sua paixão pelo rock.

Quando alguém escolhe um caminho de fazer algo que não vai ajudar a te situar em uma categoria é muito difícil. Porque para os vallenatos eu era muito moderno, e para os modernos eu era muito vallenato. Então te colocam em um lugar sempre separado. No meu trabalho, quando eu entrei na indústria e propus fazer isso, não tive muitos sorrisos [...]. Isso com os músicos, porque com o público sempre foi diferente, o público sempre gostou (Carlos Vives, entrevista, março de 2011).

Vives comenta que a humildade com que os artistas de vallenato cantam sobre a natureza, o amor, a mulher etc. sempre o cativou, mas que não é possível cantar com a mesma “magia” desses profissionais, já que está inevitavelmente inserido em outro contexto cultural. Ele faz parte da indústria, está em um sistema de mercado, sabe que não há como fugir disso e nem pretende fazê-lo: "E as pessoas me diziam: "Isso não é folclore". E eu dizia: "Vocês têm toda razão, isso não é folclore". [...] Porque é verdade, folclore é algo muito mais mágico. Meu conceito sobre folclore é diferente, eu me alimento de folclore, mas estou na indústria” (Carlos Vives, entrevista, março de 2011).

O vallenato de Carlos Vives é, assim, considerado world music. Em 2013, o artista inclusive já foi indicado pela categoria chamada "World Music" (criada em 1989). Também concorreu nas categorias: "Melhor álbum” (Corazón Profundo), "Melhor cantor masculino" e "Melhor performance ao vivo". 


\section{World music na Colômbia - anos 2000}

Diz Gómez (2015) que os estilos de música world music mais gravados atualmente estão em duas linhas na Colômbia e foram inspirados por Carlos Vives: o tropipop, que fusiona gêneros mais tradicionais da costa caribenha e elementos indígenas com sons já internacionalizados, como o pop, o rock e a NMC (Nueva Musica Colombiana). Esta última hibrida elementos de várias partes do país, principalmente da Costa do Pacífico, com estilos internacionais, a exemplo do eletrônico e do reggae.

Sobre o tropipop, o autor Blanco Arboleda (2009) explica que depois dos anos 2000 se desenvolveu uma nova tendência como resultado da influência marcante das fusões e do som de Carlos Vives: o denominado tropipop emergiu recentemente como a nova sonoridade da Colômbia. É uma fusão de rock e pop com cumbia, vallenato e outros ritmos caribenhos. É a mesma fórmula de Carlos Vives, rejuvenescida musicalmente de maneira mínima. Devido às críticas que recebeu (ser uma cópia do trabalho de Carlos Vives), o tropipop perdeu um pouco de espaço nas rádios e gravadoras. Ao contrário dele, a NMC despontou como o novo som da Colômbia no século XXI (Blanco Arboleda, 2009).

A banda Chocquibtown, exemplo de NMC, surgiu em 2006, cantou na abertura da Copa América 2011, foi indicada para o Grammy Awards duas vezes (2011 e 2015) e para o Grammy Latino sete vezes, ganhando, em 2010, com a canção De donde vengo yo, e em 2015 também, como melhor álbum em sua categoria. Chocquibtown mescla música tradicional da Costa do Pacífico com funk, hip hop, jazz etc. De donde vengo yo é uma música que mostra, segundo o cantor Tostao, a diversidade do povo colombiano para o mundo e tenta romper o estereótipo que envolve o país, associado às drogas:

A canção [...] é um retrato do nosso povo: um povo "pluriétnico" e multicultural, como é a Colômbia [...]. Também às vezes desse país só se fala coisa ruim: Pablo Escobar, a cocaína, maconha. E este país é muito mais que isso, muito mais do que as coisas negativas das que se falam nos meios massivos de comunicação. E esta ideia está colocada aí na letra: "A coisa não é fácil, mas sempre igual. Sobrevivemos” (Tostao, entrevista, março de 2011). ${ }^{19}$

Na canção mencionada, o grupo ressalta os grandes problemas enfrentados pelos colombianos todos os dias, "A coisa não é fácil”, e as diferenças sociais que são enormes, como fica exposto nos versos: “Todo mundo têm carro [...]. Menos nós”. 
Apesar de críticos, eles enfatizam o orgulho de serem colombianos e da região do Pacífico, como em "daqui se fala mal, mas tudo está muito melhor" e "temos a chuva, o frio e o calor” e a alegria da população, apesar de todos os problemas enfrentados, como a corrupção, as diferenças sociais, a pobreza, o racismo, associação do país com as drogas etc. O que se nota é que, ao mesmo tempo em que a letra demonstra a intenção de acabar com o estereótipo do país ligado às imagens negativas, também utiliza a "máscara", do lugar comum da felicidade, da festa e, até, de que aquela região seria "negra”, negando as populações indígenas que ali vivem. Como resume a frase da premiada música do grupo: "Temos problemas, mas seguimos felizes”. Pode-se concluir que, debaixo do discurso de denúncia dos problemas sociais propagados por bandas mais contestadoras da realidade política e social, como acontece com a Chocquibtown e outras latino-alternativas, estas não conseguem fugir das características básicas da categoria world music, tanto quando mesclam ritmos locais com outros mais internacionalizados ou quando se utilizam de discursos de exotismo, criados pelos países colonizadores. Como afirma Iván Benavides, em entrevista para Goméz (2015), “os mesmos grupos para entrar no mercado se disfarçam deles mesmos, da caricatura, do que espera o consumidor, que em si é a perversão da indústria, onde está o turista buscando o exótico e os músicos se autoerotizam” (Goméz, 2015, p. 41, tradução própria).

O grupo bogotano Bomba Estéreo, fundado em 2005, hibrida vários gêneros musicais, dentre eles o reggae, o rap, a cumbia e a música eletrônica, tentando trazer "um pouco de folclore com música eletrônica", como diz a letra de seu primeiro hit, chamado Fuego.

A banda foi indicada duas vezes ao Grammy Latino, em 2013 e 2015, bem como ao Grammy internacional, em 2016, pela categoria de "Melhor rock latino urbano ou álbum alternativo". Quando pergunto sobre a importância do cantor Carlos Vives, o guitarrista e fundador do grupo Simón Mejía declara que:

Definitivamente Carlos Vives é o primeiro nome que me vem à mente quando se fala em abrir essa porta para levar a música a outros públicos. Com a música folclórica colombiana sempre se teve muito cuidado, porque vem de uns lugares que estão marcados dentro de um conjunto cultural que as pessoas tendem a cuidar muito, como os antigos maestros de vallenato e de folclore, as cantoras antigas [...]. É claro que cantores como Vives mostraram a música da Colômbia para o mundo, e as pessoas que nunca tinham escutado ou nunca tinham se interessado em escutar um vallenato ou uma cumbia, através dele souberam que existiam esses 
gêneros musicais, e hoje em dia estamos colhendo os frutos disso. (Simón Mejía, entrevista, março de 2011) ${ }^{20}$

É por isso que Carlos Vives, com a iniciativa de seu vallenato híbrido expandido para o mundo, seja talvez o maior exemplo no meio musical colombiano da seguinte discussão: por um lado, há uma preocupação pelo resguardo e pela lembrança de uma outra época, por parte dos tradicionalistas; por outro, a defesa de que essa modernização no gênero o teria "revivido", trazendo-o à memória das pessoas. Além da questão da preservação versus modernização, é importante destacar outra relevante ambiguidade que a world music agrega aos países considerados de terceiro mundo: ao mesmo tempo em que existe essa restrição para que entrem para o mercado fonográfico internacional, já que precisam fazê-lo por meio da etiqueta do exótico, da alegria, do distinto etc., colocando a realidade de seus problemas sociais em segundo plano, por outro lado, esse exotismo faz com que muitas bandas locais acabem lucrando muito dinheiro e fama por trabalharem com ritmos considerados "autênticos" e diferenciados no mercado global.

\section{Conclusão}

A world music é uma categoria musical que surgiu no fim dos anos 1980 e que se utiliza de recursos e características musicais mainstream do mercado global hibridadas com características de músicas de lugares considerados autênticos e remotos, localizados em países menos desenvolvidos. Porém, tal definição não dá conta de explicar o motivo pelo qual se encontram nas playlists e CDs de gravadoras dessa categoria músicas de cidades dos Estados Unidos ou de países da Ásia ou da Europa, como a França. Surge aí a dúvida da definição do que seria ou não percebido como world music, de quais são as fronteiras do que é mainstream e do que é considerado um "local" exótico por essa categoria. Apropriar-se de músicas provenientes de um "local" particular somente é interessante quando o mercado, na pós-modernidade, fica saturado pela massificação cultural. Nessa fórmula pós-moderna, elas são transformadas em fetiches pela indústria e não é necessário conhecer as culturas que as originaram.

O mercado world music tem fronteiras muito difusas e tende a homogeneizar conceitos tão diversos e distantes como as músicas de países africanos e dos países latinos, colocando-as sob um mesmo teto: o do exótico. No mesmo sentido da utilização do "nós índios" ou da língua franca abordado neste artigo, o vallenato também 
se adaptou à indústria dos países dominantes, e seu maior representante nessa fase foi o cantor Carlos Vives. O artista foi divisor de águas e alvo de muitas críticas feitas pelos músicos que defendiam a "pureza” de uma tradição, a origem do vallenato como proveniente de um pequeno "local” tradicional e "intocado" - origem essa já desconstruída por diversos autores.

Carlos Vives, porém, não esconde sua necessidade de estar “dentro" da indústria da música e fazer parte de um contexto diferente do que existia naquela época dita "pura" e "tradicional". Ao mesmo tempo, ele enfatiza o retorno às suas raízes para delas extrair inspiração e diz que se orgulha da região em que nasceu, onde os músicos são poetas, segundo sua classificação, capazes de cantar "de improviso" o que sentiam. Assim, essa tradição pode ser reformada, traduzida, mas não pode ser perdida com o intuito de ser vendida no mercado transnacional. Os artistas se autoerotizam para poderem lucrar.

É possível concluir que a Colômbia ainda tentar redefinir o "local" através da world music, por meio do vallenato, do tropipop e, principalmente, da NMC. Esses três estilos musicais buscam construir uma nova imagem para seu país, e os artistas atuais sempre relembram a importância que Carlos Vives e seu vallenato moderno tiveram para abrir as portas à música colombiana no mercado internacional. A fórmula do tropipop seria a mesma utilizada por Vives, já a das bandas de NMC consiste em transferir o "local" do Caribe colombiano para outras regiões, como o Pacífico do país, porém a presença daquilo que traz conforto, segurança, ou seja, do folclore combinado com uma "língua franca", continua atuante. Para os países classificados como de primeiro mundo, esses ritmos latinos são atraentes somente quando estereotipados, porque passam pela lente do exótico, mas ao mesmo tempo são reconhecidos através de um denominador comum internacional.

Todos querem conhecer a Colômbia de Carlos Vives, terra na qual os problemas são esquecidos, mas não querem entender os conflitos político-sociais pelos quais o país realmente passa, ou escutar canções que discutam tais assuntos. Portanto, é somente pela etiqueta world music que muitos desses artistas podem fazer parte das playlists pelo mundo.

Recebido: 28/11/2018

Aprovado: 17/06/2019 
Laís Galo Vanzella é Mestre em Psicologia pela FFCLRP-USP, possui graduação em Comunicação Social e pós-graduação em Jornalismo Cultural pela FAAP. Há nove anos pesquisa a Colômbia através de sua música e em 2018 apresentou na USP a dissertação intitulada A memória individual e coletiva colombiana na performance de um gênero musical: o vallenato. ORCID: https: / / orcid.org/0000-0002-69808716 Contato: lavanzella@gmail.com

Francirosy Campos Barbosa é Antropóloga, professora associada no Departamento de Psicologia da FFCLRP-USP, fez pós-doutorado na Universidade de Oxford, coordenadora do GRACIAS Grupo de Antropologia em contextos islâmicos árabes, autora do livro Performances islâmicas em SP: entre arabescos, luas e tâmaras, 2017, coordenadora do livro Olhares femininos sobre o Islã: etnografias, metodologias e imagens. São Paulo, Hucitec, 2010. Diretora do documentário: Allah, Oxalá na trilha Malê, 2015. ORCID: https://orcid.org/0000-0003-00645995 Contato: francirosy@gmail.com

\section{Notas}

1. As entrevistas foram todas conduzidas e traduzidas para o português pela primeira autora.

2. As experiências de campo e as narrações de entrevistas encontradas neste artigo foram realizadas, desde o ano de 2011, pela primeira autora. A referência em primeira pessoa corresponde aos cadernos de campo e ao material de pesquisa colhido nas viagens feitas para aprofundar o estudo. 3. A pesquisa foi realizada no Departamento de Psicologia da USP de Ribeirão Preto, sob orientação da segunda autora.

4. O termo "local" aparece entre aspas neste artigo, assim como na obra de Renato Ortiz aqui abordada: Um outro território: ensaios sobre a mundialização (1996).

5. O termo mainstream, que significa "fluxo principal" na língua inglesa, "abriga escolhas de confecção de produto reconhecidamente eficientes, dialogando com elementos de obras consagradas e com sucesso relativamente garantido. Ele também implica uma circulação associada a outros meios de comunicação de massa como a TV (através de videoclipes), o cinema (as trilhas sonoras) ou mesmo a Internet" (Cardoso Filho; Janotti Júnior, 2006, p. 8).

6. O soukos é originário do Congo e é a música e estilo de dança mais popular no momento na África Subsaariana. O zouk é um estilo afro-caribenho originário das Antilhas (Nogueira da Costa, 2015). Já o rai vem do Norte da África (do Maghreb) e é uma mistura de rock, funk, reggae e música andaluz (Mourão, 2012).

7. Connell e Gibson (2004) argumentam que os países do "terceiro mundo" podem ter a opção de

Anuário Antropológico, volume 44, n.2, 2019, pp.305-328 
não entrarem no mercado global, restringindo-se à sua cultura particular. Os autores chamam isso de "estar fora" do sistema dominante, fora da cultura transnacional.

8. Para alguns antropólogos, o uso do verbo "resgatar" quando se fala de cultura ou de expressões culturais é inapropriado e impreciso, porque semanticamente é problemático assumir que uma cultura precisa "ser resgatada". Isso pode trazer implicações coloniais e, inclusive, uma ideia equivocada do "forte salvando o fraco". No entanto, neste fragmento, é conservada a terminologia usada pelo autor.

9. Putumayo. Link: https://www.putumayo.com/about.

10. Entrevista realizada com Tomas Cookman, presidente da gravadora Nacional Records, em Los Angeles, no mês de julho de 2011.

11. Entrevista realizada com o cantor Carlos Vives, em Bogotá, no mês de março de 2011.

12. A caja vallenata (“caixa vallenata”, em português) é um instrumento de formato cone tubular que lembra um tambor, pois é tocado diretamente com as mãos. Possivelmente de origem indígena, é nativo da região do Caribe, especialmente de Valledupar, cidade da Costa do Caribe colombiano (Vanzella, 2018).

13. A guacharaca é um instrumento de raspado, feito com uma cabeça oca na qual são feitas várias incisões horizontais na parte externa. Para tocar, basta friccionar as incisões com um raspador metálico chamado trinche (Vanzella, 2018).

14. O uso do termo "Costa” aparece em letra maiúscula, assim com utiliza o autor Peter Wade em sua obra aqui abordada: Music, Race and Nation (2000).

15. Para saber mais, ver Vanzella, 2018.

16. Entrevista com o famoso acordeonista Nicolas de Los Ríos, que foi escolhido pela ONU para tocar na Cerimônia da embaixada da Colômbia em 2014, uma semana após o falecimento de Gabriel García Márquez. Bogotá, fevereiro de 2016 (Vanzella, 2018).

17. Para maiores explicações sobre a ligação do governo colombiano com o vallenato, ver Vanzella, 2018.

18. A gaita hembra ("gaita fêmea", em português) é um instrumento da cultura pré-colombiana da região do Caribe colombiano. As gaitas fêmea e macho são semelhantes, exceto pelo número de orifícios: a fêmea tem cinco, e a macho, um (López Mendoza, 2005). Quando Carlos Vives decidiu utilizar a gaita hembra, foi muito difícil encontrá-la e afiná-la, já que era um instrumento totalmente em desuso (Vanzella, 2018).

19. Entrevista realizada com o cantor Tostao, um dos três vocalistas do grupo Chocquibtown, em Bogotá, no mês de março de 2011.

20. Entrevista realizada com Simón Mejía, guitarrista do grupo Bomba Estéreo, em Bogotá, no mês de março de 2011.

\section{Referências}

A ORIGEM DO AFROBEAT. 2016. Revista Raça. Disponível em: https://revistaraca.com.br/a-origem-do-afrobeat/. Acesso em: 13 agosto 2018

APPADURAI, Arjun. 1990. Disjuncture and difference in the global cultural economy. Public Culture, 
v. 2, n. 2, p. 1-24.

BARBERO, Jesús Martín; OCHOA GAUTIER, Ana María. 2001. Políticas de multiculturalidad y desubicaciones de lo popular. In: FERMÍN, Alejandro Maldonado; MATO, Daniel (orgs.). Cultura y transformaciones sociales en tiempos de globalización. Buenos Aires: CLASCO, Consejo Latinoamericano de Ciencias Sociales, p. 111-125.

Disponível em: http://bvsde.org.ni/clacso/publicaciones/EstudiosLatino america nossobrecultural .pdf. Acesso em: 7 março 2018.

BERMÚDEZ, Egberto. 2004. ¿Que es el vallenato? Una aproximación musicológica. Ensayos. Historia y teoría del arte, v. 9, n. 9, p. 9-62.

BERMÚDEZ, Egberto. 2005. "Por dentro e por fora”. In: ULHOA, M.; UCHOA, Ana María (orgs.). Música Popular na América Latina. Porto Alegre: UFRGS, p. 214-242.

BLANCO ARBOLEDA, Darío. 2005. "La Musica de la costa atlântica colombiana - Transculturalidad e identidades en Mexico y Latinoamérica”. Revista Colombiana de Antropologia, n. 41, p. 171-203. Disponível em: http: / / www.redalyc.org/ articulo.oa?id=105015281006. Acesso em: 14 junho 2017. BLANCO ARBOLEDA, Darío. 2009. De melancólicos a rumberos... de los Andes a la Costa. La identidad colombiana y la música caribeña. Boletín de Antropologia Universidad de Antioquia, v. 23, n. 40, p. 102-128. Disponível em: http: / / bibliotecadigital.udea.edu.co/dspace/handle/10495/2318. Acesso em: 14 junho 2017.

BOSI, Ecléa. 1994. Memória e sociedade: lembranças de velhos. São Paulo: Companhia das Letras.

CAIUBY NOVAES, Sylvia. 1993. Jogo de espelhos. São Paulo: Edusp.

CANCLINI, Néstor García. 2001. Culturas híbridas. Buenos Aires: Paidós.

CARDOSO FILHO, Jorge; JANOTTI JR., Jeder. 2006. A música popular massiva, o mainstream e o underground trajetórias e caminhos da música na cultura midiática. Trabalho apresentado no VI Encontro dos Núcleos de Pesquisa da Intercom.

Disponível em: http: //www.intercom.org.br/papers/nacionais/2006/resumos/R1409 -1.pdf. Acesso em: 12 setembro 2018 .

CARVALHO, José Jorge. 1991. As duas faces da tradição: o clássico e o popular na modernidade latinoamericana. Brasília: Série Antropologia.

CONNELL, John; GIBSON, Chris. 2004. World music: deterritorializing place and identity. Progress in Human Geography, v. 28, n. 3, p. 342-361. Disponível em: http:/ /www.academia.edu/1539658/ World_music_deterritorializing_place_and_identity. Acesso em: 4 setembro 2018.

COSTA, Fernando Nogueira da. 2015. Música Africana. Cidadania e Cultura [Blog].

Disponível em: https: / / fernandonogueiracosta.wordpress.com/2015/11/22/musica-africana/. Acesso em: 18 abril 2018.

CULSHAW, Peter. 2014. “Parem de falar que Fela Kuti é 'world music'”. Noisey. Disponível em: https: / / noisey.vice.com/pt_br/article/r7bapz/parem-de-falar-que-fela-kuti-e-world-music. Acesso em: 12 setembro 2018.

FIGUEROA, José Antonio. 2007. Realismo Mágico, vallenato y violencia politica en el caribe colombiano. Tese de doutorado em Filosofia, Georgetown University. Disponível em: https:/ / repository.library.georgetown.edu/bitstream/handle /10822/553237/figueroaJose.pdf?se quence=1. 
Acesso em: 9 junho 2017.

FREITAS, Carlos. 2011. "Fela Cuti: Música é a arma do futuro". Piauí. Disponível em: https://piaui. folha.uol.com.br/fela-kuti-musica-e-a-arma-do-futuro/. Acesso em: 3 outubro 2018.

GIDDENS, Anthony. 1990. The consequences of modernity. Cambridge: Polity Press.

GÓMEZ, Nathaly Goméz. 2015. Invenciones de la colombianidad: Nueva Música Colombiana. Dissertação de Mestrado em Estudos Culturais, Universidad Javeriana. Disponível em: https: / / repository.javeriana.edu.co/bitstream/handle/10554/ 16770/ ?sequence=1. Acesso em 10 maio 2017. GUERRA, Paula. 2016. Lembranças do último verão. Festivais de Música, ritualizações e identidades na contemporaneidade portuguesa. Portugal ao Espelho. Disponível em: https://portugalaoespelho.files. wordpress.com/2016/05/ficha_-lembrancas-ultimo-verao.pdf. Acesso em: 12 abril 2019.

GUILBAULT, Jocelyne. 2006. On Redefining the "Local"throughWorld Music. In: Jennifer C. Post (ed.). Ethnomusicology, a contemporary reader. New York: Routledge, p. 137-146. Disponível em: https: / /www.amherst.edu/media/view/57430/ original/Guilbault,\%20On\%20Redefining. pdf. Acesso em: 14 novembro 2017.

HALL, Stuart. 2011. A identidade cultural na pós-modernidade. Rio de Janeiro: DP\&A.

LEON RINCON, Lucero. 2016. Historia, crítica y desafíos del Partido Liberal Colombiano. Dissertação de Mestrado em Governabilidade e democracia, Universidad Santo Tomás. Disponível em: http: / / repository.usta.edu.co/bitstream/handle/ 11634/1684/Leonlucero2016.pdf?sequence=1. Acesso em: 14 setembro 2017.

LÓPEZ MENDOZA, Guillermo. 2005. Colômbia e sua música. Bogotá: Grupo Carvajal.

MOURÃO, Lucas. 2012. Uma volta pela música do Maghreb - parte 1:Argélia.Volta ao Mundo musical [Blog]. Disponível em: http://voltaaomundomusical.blogspot. com/2012/03/uma-volta-pela-musica-do-maghreb-parte.html. Acesso em: 15 agosto 2018.

ORTIZ, Renato. 1996. Um outro território - ensaios sobre a mundialização. São Paulo: Olho d'Água.

PACINI-HERNANDEZ, Deborah. 1993. A view from the south: Spanish Caribbean perspectives on world beat. The World of Music, v. 35, n. 2, p. 48-69.

PORTACCIO, José Fontalvo. 2010. Colombia y su música. Bogotá: Disformas Triviño.

VANZELLA, Laís Galo. 2011. Hibridação musical: o processo de modernização e internacionalização dos ritmos colombianos tradicionais cumbia e vallenato. Trabalho de Conclusão de Curso de Graduação em Comunicação Social, Fundação Armando Alvares Penteado - FAAP.

VANZELLA, Laís Galo. 2018. A memória individual e coletiva na performance de um gênero musical: o vallenato. Dissertação de Mestrado em Psicologia, Universidade de São Paulo - USP.

WADE, Peter. 2000. Music, race and nation. Chicago: University of Chicago Press. 
Resumo: Este artigo tem como objetivo apresentar o que é a categoria world music e como ela se perfilou especificamente na Colômbia através do gênero musical "local" vallenato e dos novos estilos de fusões musicais colombianas que surgiram nos anos 2000. Na Colômbia, o vallenato world music da década de 1990 ajudou a redefinir uma imagem midiática mais favorável do país pelo mundo. $\mathrm{Na}$ atualidade, a fórmula da hibridação de músicas folclóricas com sons mainstream ainda é tendência no mercado musical colombiano. Para os países classificados como primeiro mundo, tais ritmos latinos são atraentes somente quando vistos por meio da máscara do exótico, do estereótipo. Assim, esse é um recurso que os próprios músicos acabam utilizando para poderem vender seu produto globalmente.

Palavras-chave: World music; vallenato; Carlos Vives; Colômbia; local.
Abstract: This article aims to present what is the world music category and how it was specifically shaped in Colombia through the "local" musical genre vallenato and the new styles of Colombian musical fusions that emerged in the 2000s. In Colombia, vallenato world music of the 1990s helped to redefine a more favorable media image of the country around the world. Currently, the formula of the hybridization of folk songs with mainstream sounds is still a trend in the Colombian musical market. For countries classified as the first world, such Latin rhythms are appealing only when seen through the mask of the exotic, the stereotype. Thus, this is a feature that the musicians themselves use to sell their product globally.

Keywords: World music; vallenato; Carlos Vives; Colombia; local. 